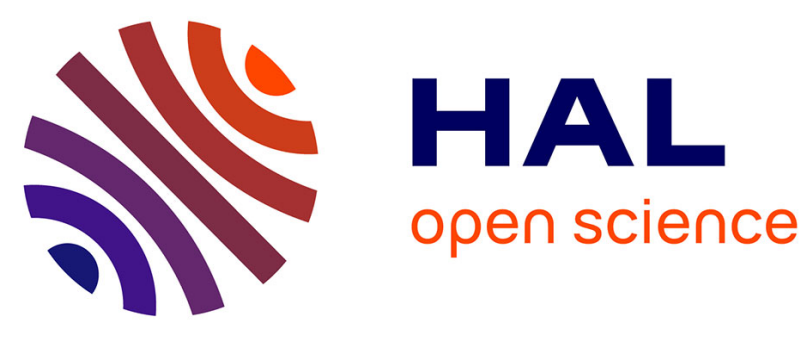

\title{
Cytological evidence for automictic thelytoky in parthenogenetic oribatid mites (Acari, Oribatida): Synaptonemal complexes confirm meiosis in Archegozetes longisetosus
}

Paavo Bergmann, Michael Laumann, Roy A. Norton, Michael Heethoff

\section{To cite this version:}

Paavo Bergmann, Michael Laumann, Roy A. Norton, Michael Heethoff. Cytological evidence for automictic thelytoky in parthenogenetic oribatid mites (Acari, Oribatida): Synaptonemal complexes confirm meiosis in Archegozetes longisetosus. Acarologia, 2018, 58 (2), pp.342-356. 10.24349/acarologia/20184246 . hal-01715299

\author{
HAL Id: hal-01715299 \\ https://hal.science/hal-01715299
}

Submitted on 22 Feb 2018

HAL is a multi-disciplinary open access archive for the deposit and dissemination of scientific research documents, whether they are published or not. The documents may come from teaching and research institutions in France or abroad, or from public or private research centers.
L'archive ouverte pluridisciplinaire HAL, est destinée au dépôt et à la diffusion de documents scientifiques de niveau recherche, publiés ou non, émanant des établissements d'enseignement et de recherche français ou étrangers, des laboratoires publics ou privés.

\section{()ㅜ) $\Theta$}

Distributed under a Creative Commons Attribution - NoDerivatives| 4.0 International 


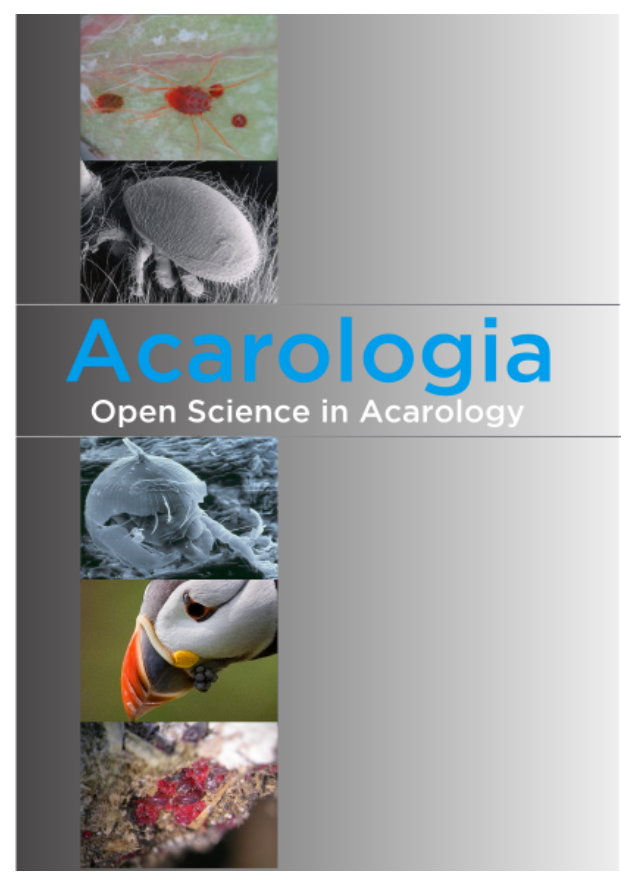

\section{Acarologia}

A quarterly journal of acarology, since 1959

Publishing on all aspects of the Acari

All information:

http://www1.montpellier.inra.fr/CBGP/acarologia/ acarologia@supagro.inra.fr

\section{OPEN ACCESS}

\section{Acarologia is proudly non-profit, with no page charges and free open access}

Please help us maintain this system by encouraging your institutes to subscribe to the print version of the journal and by sending us your high quality research on the Acari.

Subscriptions: Year 2018 (Volume 58): $380 €$ http://www1.montpellier.inra.fr/CBGP/acarologia/subscribe.php

Previous volumes (2010-2016): $250 €$ / year (4 issues)

Acarologia, CBGP, CS 30016, 34988 MONTFERRIER-sur-LEZ Cedex, France

The digitalization of Acarologia papers prior to 2000 was supported by Agropolis Fondation under the reference ID 1500-024 through the « Investissements d'avenir » programme

(Labex Agro: ANR-10-LABX-0001-01)
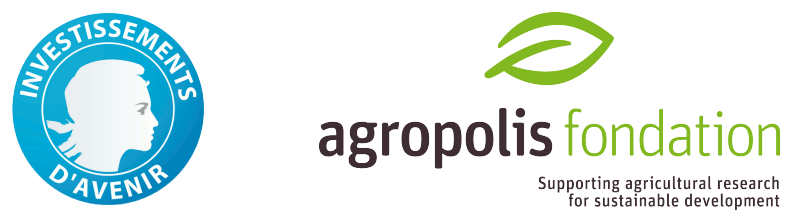

Acarologia is under free license and distributed under the terms of the

Creative Commons-BY-NC-ND which permits unrestricted non-commercial use, distribution, and reproduction in any medium, provided the original author and source are credited. 


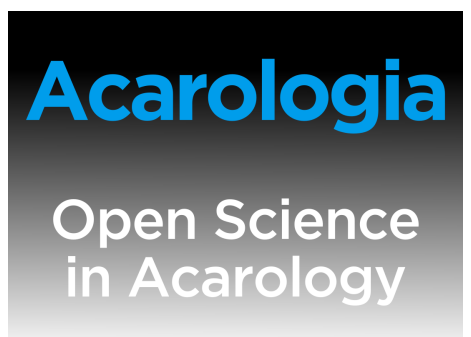

Received 03 May 2017

Accepted 25 October 2017

Published 22 Februery 2018

Corresponding author

Paavo Bergmann:

paavo.bergmann@uni-konstanz.de

Academic editor

Lise Roy

DOI

10.24349/acarologia/20184246

(c) Copyright

Bergmann P. et al.

Distributed under

Creative Commons CC-BY 4.0

\section{Cytological evidence for automictic thelytoky in parthenogenetic oribatid mites (Acari, Oribatida): Synaptonemal complexes confirm meiosis in Archegozetes longisetosus}

\author{
Paavo Bergmann ${ }^{a, b}$, Michael Laumann ${ }^{a, b}$, Roy A. Norton ${ }^{c}$, \\ Michael Heethoff ${ }^{b, d}$ \\ ${ }^{a}$ Electron-Microscopy Center, University of Konstanz, Universitätsstrasse 10, D-78457 Konstanz, \\ Germany. \\ ${ }^{b}$ Institut für Evolution und Ökologie, Abteilung Evolutionsbiologie der Invertebraten, Eberhard-Karls \\ Universität Tübingen, Auf der Morgenstelle 28E, D-72076 Tübingen, Germany. \\ ${ }^{c}$ State University of New York College of Environmental Science and Forestry, 1 Forestry Drive, \\ Syracuse, NY 13210, USA. \\ ${ }^{d}$ Ecological Networks, Technische Universität Darmstadt, Schnittspahnstr. 3, 64287 Darmstadt, Germany.
}

\section{ABSTRACT}

Diplo-diploid parthenogenesis (thelytoky) is a widespread phenomenon in the mite taxon Sarcoptiformes, and is unusually frequent in the suborder Oribatida, where it characterizes almost $10 \%$ of extant species, including whole genera and families. Based on molecular and cytological data, terminal fusion automixis with an inverted meiotic sequence based on holokinetic chromosomes has been suggested as the reproductive mode in these mites. However, unequivocal structural evidence for meiosis is missing. The model organism Archegozetes longisetosus, a thelytokous member of the parthenogenetic family Trhypochthoniidae, was studied to gain ultrastructural insight in oocyte progression and meiotic processes. In this study, ovarian nuclear organization of its tritonymphal instar was examined by transmission electron microscopy (TEM). Numerous synaptonemal complexes were observed in the ovary, unequivocally confirming automixis (meiotic thelytoky) in oribatid mites for the first time. No recombination nodules were found. The nuclei are transcriptionally active in late prophase. Inverted meiosis is discussed as a result of the spatial arrangement of chromatid segregation.

Keywords achiasmate meiosis, holokinetic chromosomes, "ancient asexuals", diakinesis failure, prophasic arrest, unisexual

\section{Introduction}

The synaptonemal complex (SC) (Moses, 1956a) is a highly structured protein aggregation that is observed specifically during the prophase of meiosis I in most eukaryotes (Marec, 1996; Page and Hawley, 2004). It is associated with the pairing of homologous chromosomes during the zygotene and pachytene prophase stages, which is the prerequisite for all processes linked to meiotic recombination, and thus plays a crucial role in any form of sexual reproduction. Its function is to provide a scaffold for the stable spatial arrangement of corresponding DNA sequences, which enables the action of enzymes effecting recombination as well as segregation (Page and Hawley, 2004; Zetka, 2009).

The 60 years since the discovery of this structure in spermatocytes of crayfish (Moses, 1956b) have seen much discussion as to the causal linkage and interdependence of processes 
like double-stand breakage (DSB), crossing over, recombination and initiation of the formation of the SC. While some studies indicate DSBs to be essential for the formation of the SC (Henderson and Keeney, 2004), others point to the SC as being the prerequisite for the initiation of DSBs and subsequent recombination (McKim et al., 2002; Colaiácovo, 2005). Recombination itself seems correlated with the occurrence of electron-dense, ellipsoid protein bodies linked to the central element of the SC, the so-called recombination nodules (Carpenter, 1975; Carpenter, 1979a; Carpenter, 1979b). Formation of the SC itself, however, seems not to be directly linked to chiasmata formation and was also reported from achiasmate meiosis in insects (Welsch, 1973; Marec, 1996) as well as mammals (de la Fuente et al., 2007), where recent data suggest regulatory functions in bivalent formation (Qiao et al., 2012).

The restriction of the occurrence of the SC to the meiotic prophase, on the other hand, means that where there is a SC, there is meiosis. This study focuses on the diagnostic value of the SC to distinguish between different forms of unisexual propagation. "Asexuality" in its narrow sense means propagation without the use of gametes. In its broader sense, it includes gametedriven propagation without inter-individual genetic transfer (Parthenogenesis). Diploid females producing diploid offspring (Thelytoky) can do so either without meiosis, sporting a mitotic germ line (Apomixis), or with a meiotic germ line and reconstitution of diploidy from their own material (Automixis). All reported cases of long-term stable, obligate parthenogenesis, that were termed "evolutionary scandals" (Maynard Smith, 1978), or simply "ancient asexuals", belong to one of these last two classes. We report for the first time the occurrence of SCs in a parthenogenetic (thelytokous) species of oribatid mites, a group renowned for having an unusually high proportion (nearly 10\%) of suspected or confirmed obligately thelytokous species (Palmer and Norton, 1991). Many of these species comprise phylogenetic clusters (clades) of various size, indicating multiple possible radiations in the absence of sex (Maraun et al., 2004; Cianciolo and Norton, 2006). Some of the largest parthenogenetic clades are in the middle-derivative hyporder Nothrina ('Desmonomata' sensu lato), accounting for nearly $70 \%$ of all species in the group. The apparent old age of these clades, as estimated using molecular clock techniques (Heethoff et al., 2007b) led to their designation as putative "ancient asexuals", together with bdelloid rotifers and darwinuliid ostracods (Schön and Martens, 2002; Schwander 2016).

Considering the different long-term genetic consequences, the specific cytogenetic pathway through which female zygotes are initiated is of crucial importance. The putatively ancient parthenogenetic clade of bdelloid rotifers (Mark Welch and Meselson, 2000, but see Schwander 2016) are confirmed apomicts (mitotic germ line). However, the case has been unclear for the various clades of parthenogenetic oribatids. Apomixis was reported in few cases, but mostly treated as preliminary hypotheses, as some data are more consistent with automixy (Wrensch et al., 1994).

To better understand oogenesis and the meiotic processes in oribatid mites, we studied the last juvenile instar (tritonymph) of the diplo-diploid desmonomatan oribatid mite Archegozetes longisetosus Aoki, 1965 (Trhypochthoniidae), a model mite species (Heethoff et al., 2013). This parthenogenetic species appears quasi-clonal, with fixed heterozygosity and therefore was first hypothesized to be apomictic or to have a nonsegregative automixis (Palmer and Norton, 1992). The type of parthenogenesis in a confamilial species, Trhypochthonius tectorum (Berlese, 1896) and in Platynothrus peltifer (C.L. Koch, 1839; Crotoniidae) appears to be terminal fusion automixis (Taberly, 1987; referred to as mixocinèse), albeit solely based upon the interpretation of chromosome segregation in late metaphase using light microscopy. The observed fixed heterozygosity in A. longisetosus is incongruent with such a mechanism, except in the case of inverted meiosis (achiasmate at least for all coding regions, and with an inversed order of meiotic divisions where reductional division is preceded instead of followed by equational division; Wrensch et al., 1994). Up to now, proof of unequivocally meiotic ultrastructural features has not been available for this or any other parthenogenetic oribatid mite. Expulsion of a polar body during late previtellogenesis, as well as transient chromosome condensation indicating a second, incomplete division, indicating terminal fusion 
automixis, was reported from adult specimens of $A$. longisetosus earlier (Laumann et al., 2008), but distinct characteristic features of early meiotic prophase could not be observed in adult females. Examination of juvenile instars of $A$. longisetosus indicated the proliferation of oocytes from oogonia already during the deutonymphal stage (Bergmann and Heethoff, 2012). Microtomographic studies on the development of the genital organs indicated the beginning of previtellogenesis in peripheral oocytes of tritonymphs shortly before molting to the adult stage, but did not permit analysis of nuclear features (Bergmann et al., 2008).

Therefore, we studied the nuclei of oocytes in tritonymphal ovaries by transmission electron microscopy (TEM) to test the hypothesis of automixis by attempting to locate and examine ultrastructural features of meiotic prophase during the early stages of oocyte development in A. longisetosus. As we show in this study, SC formation in the oocytes of middle aged tritonymphs demonstrates meiotic prophase to start in the last subadult instar, prior to the onset of previtellogenesis. Further, the presence of SCs in A. longisetosus rules out apomixis as the reproductive mechanism underlying clonality.

\section{Materials and methods}

\section{Rearing}

Archegozetes longisetosus was cultured on a mixture of plaster-of-Paris and powdered charcoal (6:1 parts by volume) cast at a thickness of $4 \mathrm{~cm}$ in $150 \mathrm{ml}$ plastic screw cap jars. The vessels were covered with fine-mesh $(40 \mu \mathrm{m})$ synthetic gauze and closed with a perforated lid. The culture vessels were stored in constant dark at $21-23^{\circ} \mathrm{C}$ and checked twice a week for sufficient moisture. Bark of deciduous trees covered with unicellular green algae was provided ad libitum as a food source and replaced regularly with the moisture checks. Animals for processing were collected with a fine brush from molting aggregations prior to the appropriate instar and kept separated under the same conditions as described above in 12-well tissue culture plates until fixation.

\section{Microscopy}

Specimens for microscopy were submersed in pre-chilled $\left(0^{\circ} \mathrm{C}\right)$ modified Karnovsky's solution $\left(1.3 \%\right.$ formaldehyde, $1.66 \%$ glutardialdehyde, $4 \%$ sucrose, $6.6 \mu \mathrm{M} \mathrm{MgSO}_{4}$ in $0.05 \mathrm{M}$ sodium 4-(2-hydroxyethyl)-1-piperazineethanesulphonic (HEPES) acid buffer at $\mathrm{pH} 7.8$ ). The fixative was prepared directly beforehand using freshly depolymerised paraformaldehyde (Fluka, Buchs, Switzerland) and EM-grade glutardialdehyde 25\% (Science Services, Munich, Germany). Specimens were punctured with a fine tungsten needle (Norton and Sanders 1985) upon submersion and fixed for $90 \mathrm{~min}$ at $0^{\circ} \mathrm{C}$ and slight vacuum of approx. 300mbar. After rinsing three times for 10 minutes each in ice-chilled 0,05M HEPES buffer, postfixation was conducted in $1 \% \mathrm{OsO}_{4}$ in $0.05 \mathrm{M}$ HEPES buffer at $\mathrm{pH} 7.8$ and $0^{\circ} \mathrm{C}$ for $60 \mathrm{~min}$. After another rinsing step, the samples were dehydrated in a graded ethanol series, including en-bloc-staining with uranyl acetate, and embedded in Araldite Cy212 (plano GmbH, Wetzlar, Germany), using acetone as intermedium. A detailed description of the process is given in Bergmann et al. (2010).

Ultrathin sections of 50nm and 60nm thickness were cut using a Reichert Ultracut (LeicaJung, Vienna, Austria) microtome and diamond knives (diatome $45^{\circ}$, Biehl, Switzerland), and mounted on single slot copper grids (Science Services, Munich, Germany) coated with polyvinyl formal (Formvar, Monsanto Chemical Company, St Louis, Missouri, USA). The sections were poststained with uranyl acetate for 20-40 min and lead citrate for $90 \mathrm{sec}$ (Venable and Coggeshall, 1965), and examined with a Siemens Elmiskop 1A (Siemens \& Halske, Berlin, Germany) transmission electron microscope at $80 \mathrm{kV}$. Images were recorded with an attached $6.5 \times 9 \mathrm{~cm}$ plate camera on SO-163 electron image film (KODAK, Rochester, New York, USA). Original negatives were scanned, and images digitally scaled and processed using 
the programmes iTEM (Olympus Soft Imaging Solutions GmbH, Münster, Germany), GIMP 2.6.10 (GNU Image Manipulation Program, Copyright (C) 1995-2008 Spencer Kimball, Peter Mattis and the GIMP development team) and ImageJ (Wayne Rasband, National Institutes of Health, USA; ImageJ is in the public domain). Stitching of adjacent images was performed via elastic alignment, using the ImageJ plugin TrakEM2 (Saalfeld et al., 2010; Cardona et $a l ., 2012$ ) Measurements of SC structures also were taken in iTEM and ImageJ. Additional images were recorded on a Zeiss EM 912 Omega transmission electron microscope (Zeiss, Oberkochen, Germany), and captured with a Tröndle slow scanning digital camera (TRS Tröndle Restlichtverstärker Systeme, Moorenweis, Germany).

\section{Results}

\section{Tritonymph, 2-3 days after moulting}

Sections from the ovary show a single layer of flattened somatic cells with interphase nuclei surrounding a dense mass of germ line cells. Filiform protrusions of the germ cells containing numerous microvilli almost fill a central hollow which apparently is closed by one or few somatic cells ventro-medially (Figure 1). These somatic cells are separated from the germ cell cluster by a basal lamina (Figure $1 \mathrm{~b}$ ). Germ cells are easily recognizable by the occurrence of prominent synaptonemal complexes (SCs). All germ cells show SCs in various stages of development: Centrally located cells tend to be smaller and have smaller nuclei with less prominent SCs, probably representing early stages. Peripherally situated cells are generally larger, and have larger nuclei featuring fully developed SC figures with all typical components. This configuration is diagnostic of the pachytene stage of meiotic prophase I. Large cells in the periphery of the ovary possess large, electron lucent nuclei with indistinct or absent SC sections, and frequently one or two dense masses of chromatin. These cells probably represent a further developed diplotene stage, where degradation of the SC already occurs (Figures 1b, $2 b)$.

The fully developed SCs at pachytene (Figures 2a, 3) consist of central elements, transverse fibers and lateral elements surrounded by dense chromatin masses. Lateral elements of 11-23nm width are approximately 90-130nm apart, and regular transverse elements of 3-6nm thickness in the electron-light space between lateral and central elements occur at intervals of approx. 13-14nm. Central elements stain very electron dense. Longitudinal sections of SC show central elements as more or less parallel lines of dense structures separated by a slightly less electron dense zone (Figure 3a-e). In several sections, the central structure exhibits regularly appearing spots of higher density in intervals of $17-35 \mathrm{~nm}$. The whole central zone has a width of $24-36 \mathrm{~nm}$. Transverse sections of SC appear as electron lucent, sharply defined circles surrounded by a thin, electron dense, fibrous layer, and dense masses of chromatin (Figures 2, 3a-c,f,g). In the center of the electron lucent zone, dark spots indicate transverse sections of two, or in several cases, four central elements in a rhombic configuration, indicating the formation and presence of tetrads. Round and ellipsoid transverse sections of SC found in the images could either be due to developmental stages of SC formation, or slanted angles of sectioning. The dimensions of round transverse sections, or the short diameter of ellipsoid ones, respectively, correspond to measurements taken from longitudinally sectioned SCs.

No dark structures resembling recombination nodules were observed on a total length of $75.4 \mu \mathrm{m}$ of SC from 221 locations where SCs clearly appear as partially longitudinally sectioned, represented on four sections from $18 \mu \mathrm{m}$ apart each in the sectioning series. Small patches of electron dense materials were observed attached to the central element in several sections.

\section{Tritonymph, 5 days after moulting, and young adults}

Middle-aged tritonymphs show large germ cells featuring large, electron-lucent nuclei with prominent single or double nucleoli, and without prominent SCs (Figure 4). In these specimens, 


\section{Acarologia}
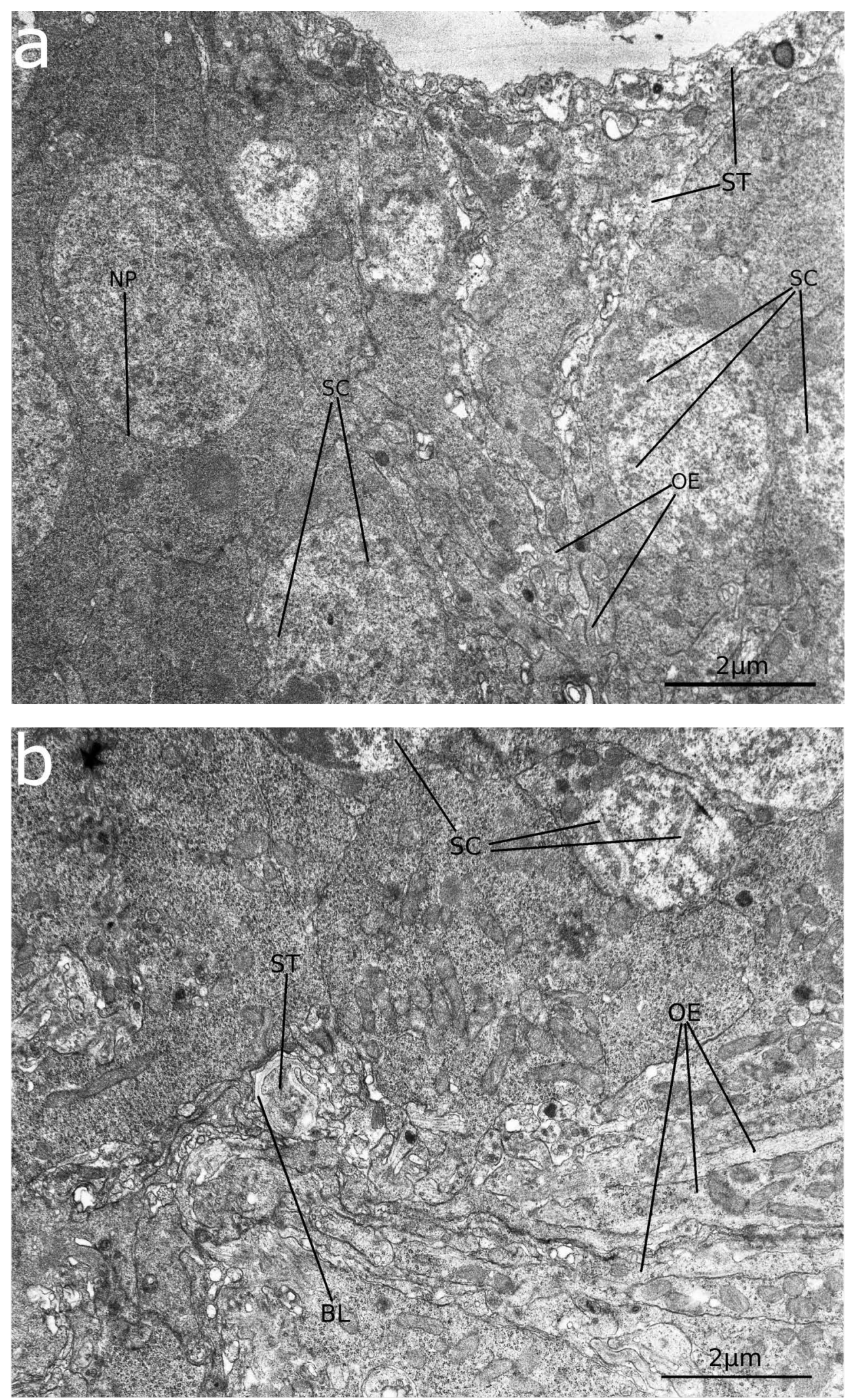

Figure 1 Archegozetes longisetosus. Overview of the arrangement of germ cells and somatic tissue in the ovary of a two day old tritonymph $\mathrm{a}$ - Rostro-medially; $\mathrm{b}$ - centrally in the ovary. Abbreviations: BL: basal lamina, NP: nuclear pores, OE: oocyte extension, SC: synaptonemal complex, ST: somatic tissue. 


\section{Acarologia}
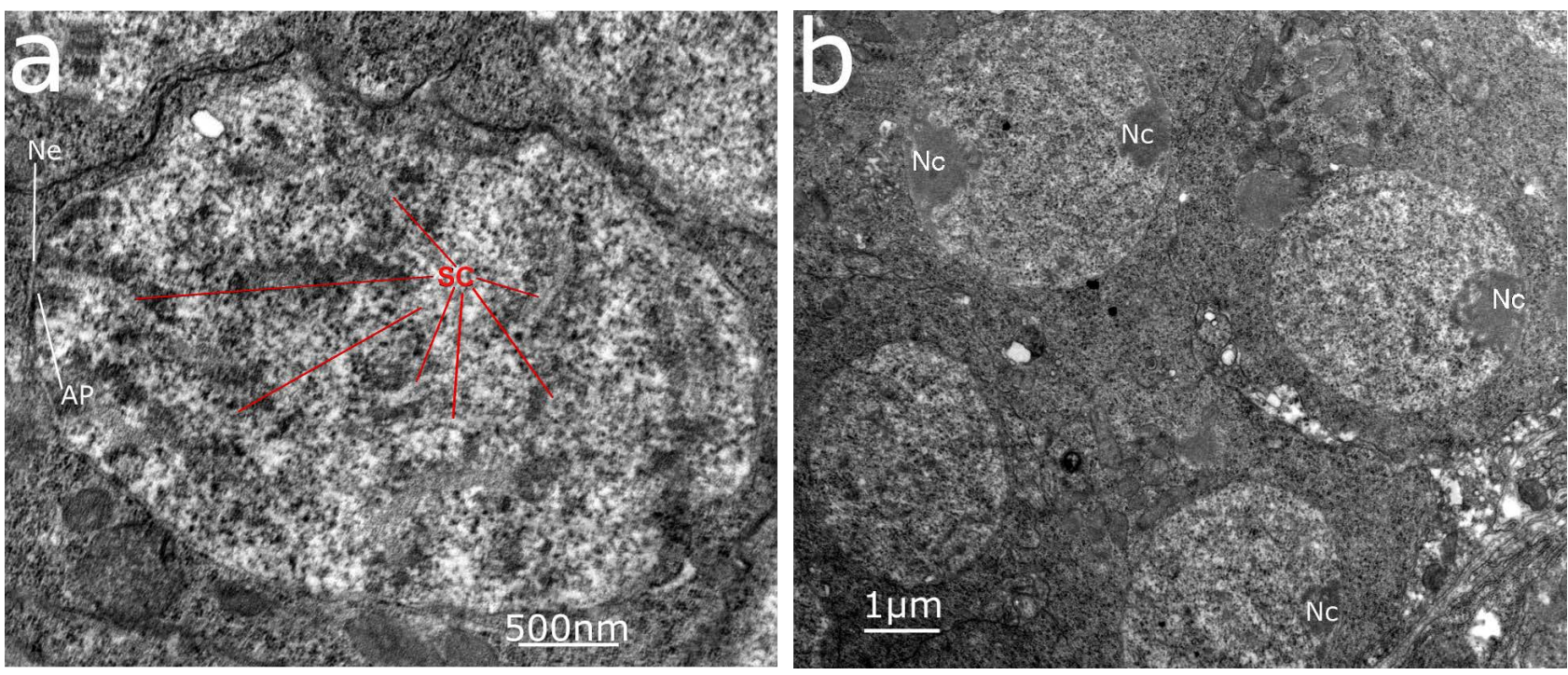

Figure 2 Archegozetes longisetosus. Germ cells in meiotic prophase of a two day old tritonymph: a - Pachytene cell with SC attached to the nuclear envelope; $b$ - putative later stage with prominent nucleoli, from more peripheral region of the ovary. Abbreviations: AP: attachment plaque, Nc: nucleolus, SC: synaptonemal complex.

as in young adults, peripheral oocytes are generally larger than those situated centrally in the ovary. Central germ cells are smaller, and their nuclei feature a patchy pattern of dense chromatin agglomerations in a semi-lucent, fibrous nuclear content. Both chromatin configurations are thought to represent different stages of diplotene progression. The filiform extensions of growing peripheral germ cells reach between the smaller central germ cells to the central medulla of the ovary (Figure 4). The content of parallel bundles of microtubules extends towards the nuclear envelope in these cells, with regions of the nuclear envelope neighboring the microtubule bundles being equipped with a dense hexagonal pattern of nuclear pores (Figure 5). Numerous nuclear pores also appear in oocytes of adults during previtellogenesis and vitellogenesis (Figure 6). The microtubule-rich extensions connecting oocytes in the rhodoid to the medulla disappear with onset of previtellogenesis and the movement of oocytes towards the ovarial meroi.

\section{Discussion}

Exclusively female clades are exceptionally frequent among oribatid mites of the group Nothrina when compared to the average for metazoans (Palmer and Norton, 1990; Maraun et al., 2004; Cianciolo and Norton, 2006). The exact nature of reproduction for any thelytokous oribatid mite has not yet been demonstrated in all details, but molecular data show no apparent signatures of recombination and indicate clonality (Palmer and Norton, 1992; Heethoff et al., 2000; Schaefer et al., 2006). This is surprising since other molecular data suggest that several clades have propagated unisexually for at least 100 million years (Heethoff, 2007b), and even have radiated in this mode (Maraun et al., 2004; Laumann et al., 2007; Heethoff et al., 2011).

The existence of prominent synaptonemal complexes throughout the tritonymphal ovarium is interesting because it provides the first direct ultrastructural proof of automixis in oribatid mites. Formation of SCs is an important constituting factor of meiotic prophase I, occurring exclusively in this stage of the germ cell cycle in oocytes and spermatocytes of most species studied so far (Marec, 1996; Page and Hawley, 2004). Terminal fusion automixis-which was reported earlier from histological studies of oribatid mite species (Taberly, 1987; termed "mixocinèse") - was proposed in A. longisetosus through histological observations of oogenesis 

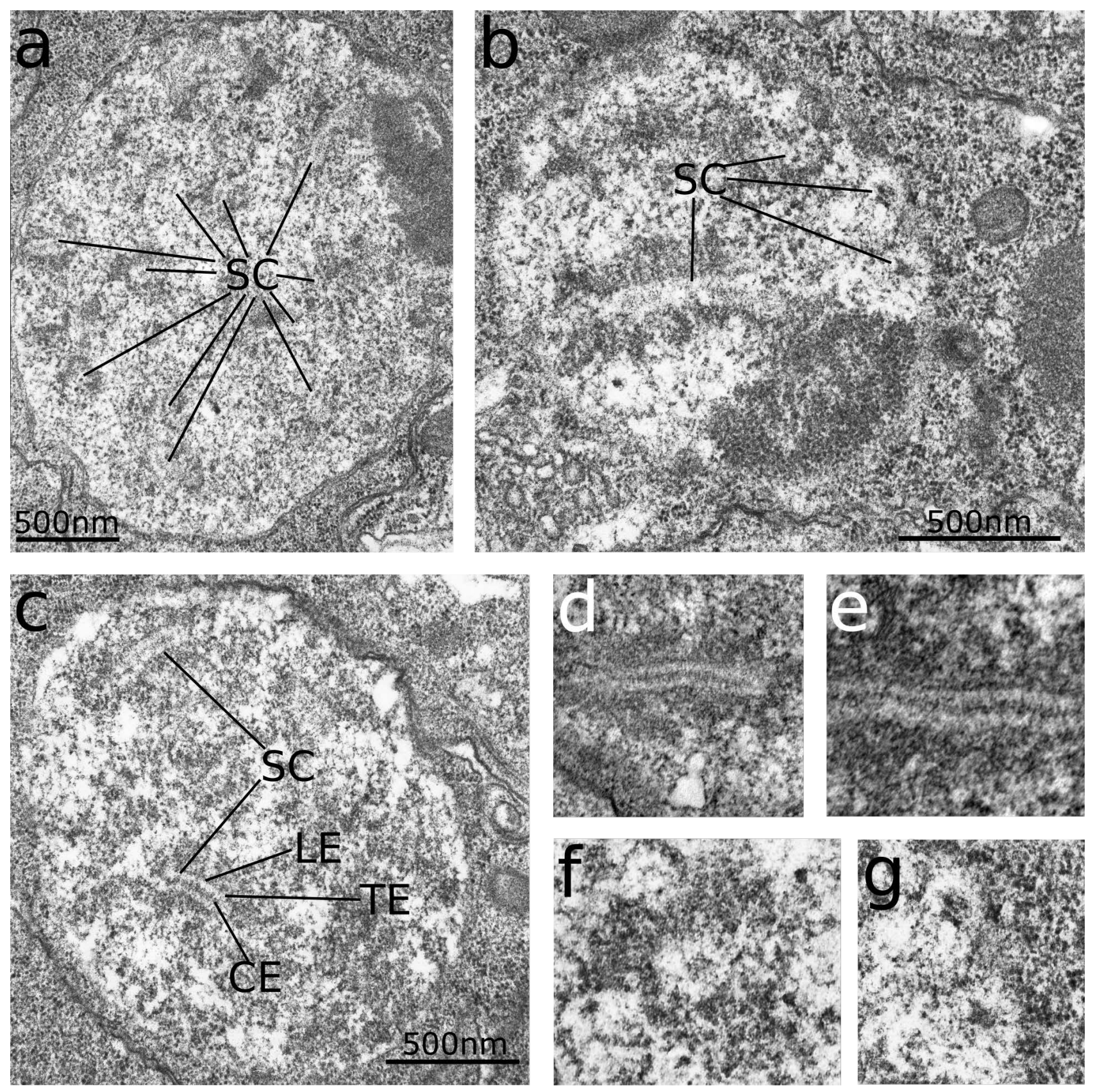

Figure 3 Archegozetes longisetosus. Synaptonemal complexes in oocytes of a two day old tritonymph: a-c: Three pachytene nuclei; d-g details: Synaptonemal complexes in longitudinal (d), (e), and transversal (f), (g) section. Abbreviations: CE: central element, LE: lateral element, SC: synaptonemal complex, TE: transversal element. 


\section{Acarologia}
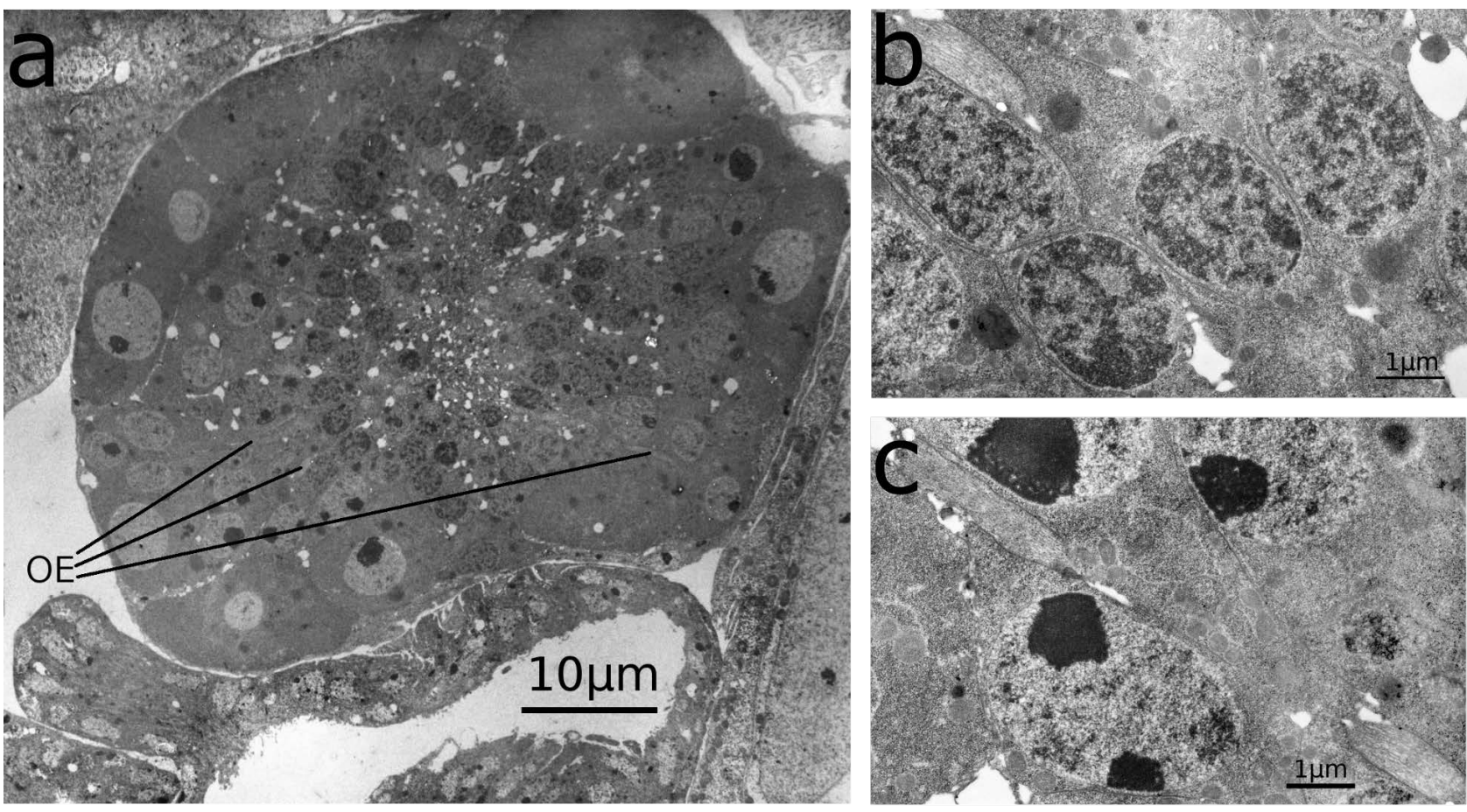

Figure 4 Archegozetes longisetosus. Ovary of a 5 day old tritonymph: a - Overview, parasagittal plane; b - detail of central region; c-detail of peripheral region. Nuclei in different diplotene stages, oocyte extensions of peripheral oocytes reach between central oocytes. Abbreviation: OE: oocyte extensions.

(Laumann et al., 2008), although nuclear structures characteristic for meiotic prophase I could not be demonstrated in adult females with certainty. This is explained by the occurrence of SC simultaneously throughout the ovary of middle-aged tritonymphs. While the ovary in the deutonymphal stage indicates proliferation of germ cells (Bergmann and Heethoff, 2012), an abundance of SCs indicates that germ cells reach their final number in the tritonymph, enter meiosis early in this last subadult instar, and remain arrested in meiotic prophase during late tritonymphal and early adult stages until their sequential activation during the adult reproductive lifespan.

Mediation of the apparent prophasic arrest and sequential activation of oogenesis is not yet understood, but its effects are seen in the mite's life-history. A. longisetosus exhibits iteroparity, with a recorded maximum of about 320 eggs laid during the lifetime of one individual in batches of about 15-30 eggs at intervals of 10-12 days (Estrada-Venegas et al., 1999; Heethoff et al., 2007a). A further consequence is that the adult ovary no longer constitutes a germarium, as no oogonia in premeiotic mitoses were found. This was speculated earlier (Bergmann et al., 2008), based solely on the absence of signs of cell division, such as metaphase plates or breakdown of the nuclear envelope, in the central part of the ovary. The radially patterned central part is not involved in vitellogenesis and was hence termed the rhodoid for its appearance to avoid misleading terminology (Bergmann et al., 2008; Bergmann and Heethoff, 2012).

\section{Transcription and RNA transport}

Although ultrathin sections did not provide unequivocal evidence of single-strand DNA loops, the existence of prominent nucleoli between late pachytene and diakinesis, as well as the abundance of nuclear pores during meiotic stages from late prophase I until the onset of embryogenesis (Figure 5 and 6), suggest the existence of lampbrush chromosomes enabling a high rate of RNA transcription during late prophase. Structural similarities exist with the 


\section{Acarologia}

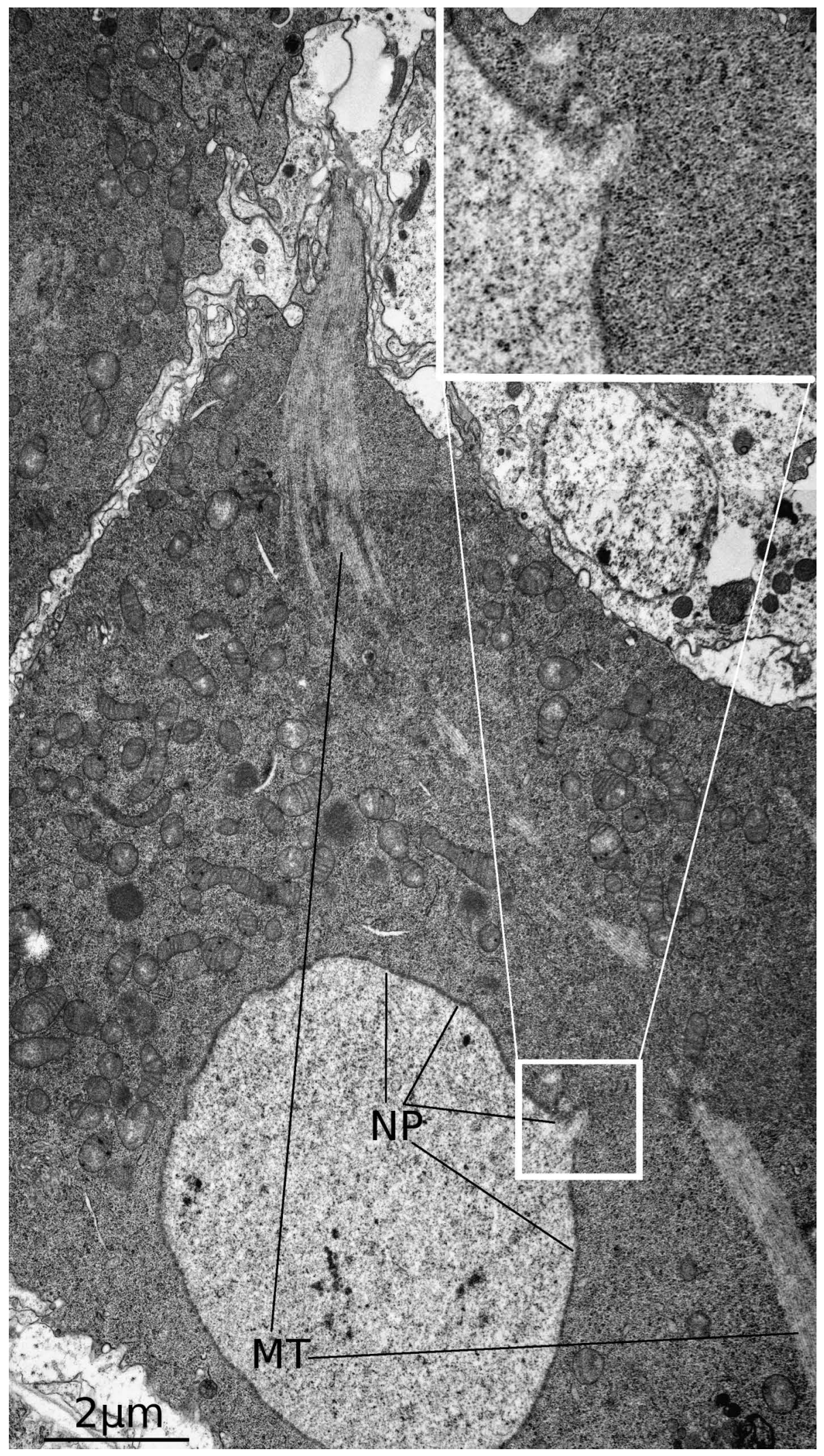

Figure 5 Archegozetes longisetosus. Peripheral oocyte of a tritonymph, showing oocyte extension and dense bundle of microtubuli passing the vicinity of the nuclear envelope. Nuclear envelope with numerous nuclear pores. Abbreviations: MT: microtubuli, NP: nuclear pores. 


\section{Acarologia}
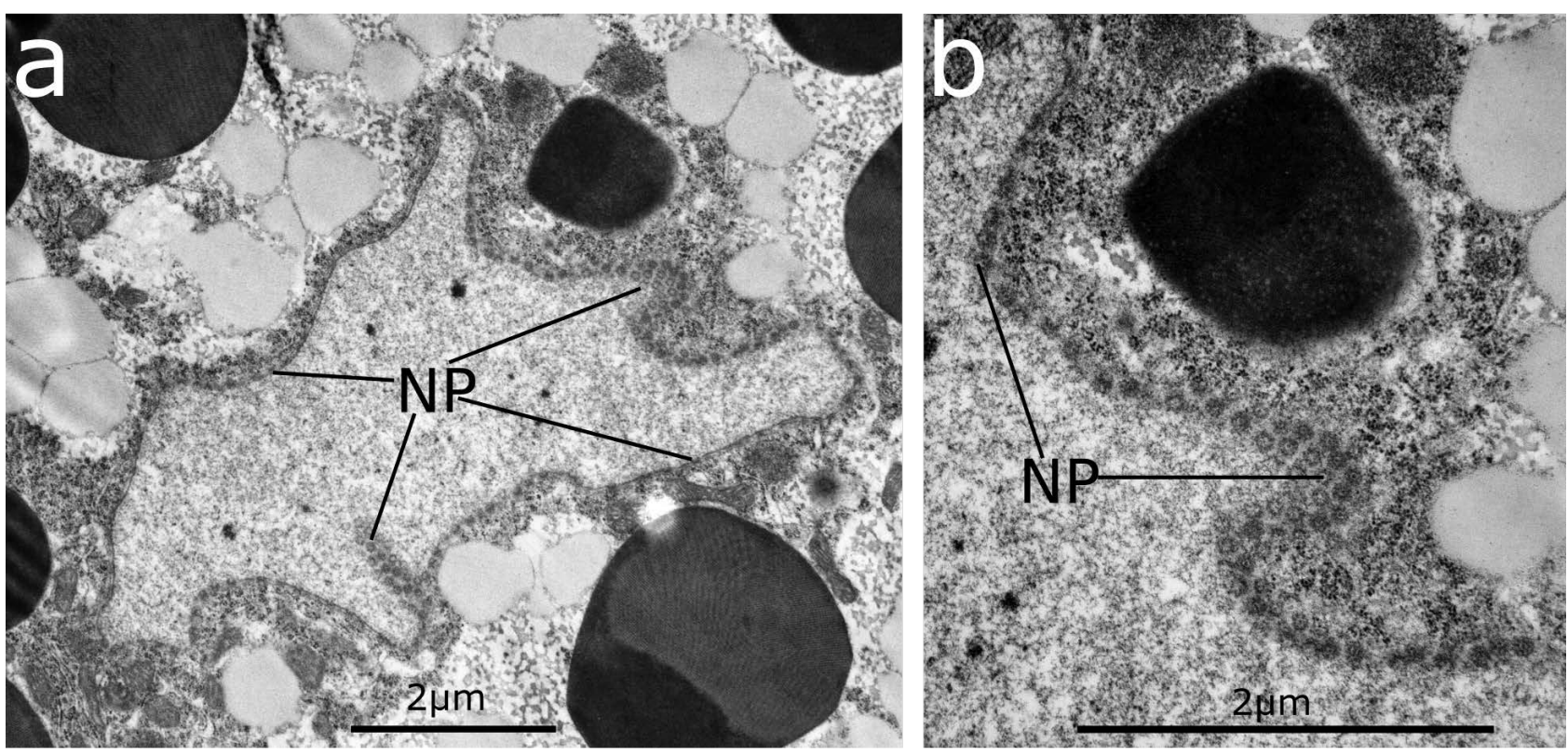

Figure 6 Archegozetes longisetosus: a - Vitellogenetic oocyte from the ovary of an adult female; $\mathrm{b}$ - Nuclear envelope with numerous nuclear pores. Abbreviation: NP: nuclear pores.

lampbrush chromosomes described in the insect Panorpa communis Linnaeus, 1758, for example the halo of electron-dense protein agglomerations peripherally of the lateral elements of the bivalent (Welsch, 1973; Bogolyubov, 2007). Despite their structural differences due to the phylogenetically distant relationship to Hexapoda, functionally panoistic ovaries were proposed earlier for A. longisetosus based on histological evidence (Bergmann et al., 2010). This latter study also reported a massive build-up of ribosomes during previtellogenesis. Ribosome accumulation during panoistic oogenesis further indicates transcriptional activity, and permits the denomination of single or double dense chromatin structures, exhibiting three structurally distinguishable portions, as true nucleoli.

An important indication of transcription coupled with extranuclear RNA export is the observed density of nuclear pores in late prophase oocytes, especially in the vicinity of microtubule bundles associated with oocyte extensions towards the medulla of the rhodoid (Figure 5). The abundance of nuclear pores persists throughout previtellogenesis and during vitellogenesis in the adult mite (Figure 6), indicating transcriptional activity during prophases of meiosis I \& II, as meiotic processes are completed during that stage (Bergmann et al., 2010; Laumann et al., 2010). This further supports the idea that chromosomes exhibit a lampbrush configuration during a considerable part of meiosis in A. longisetosus.

Although microtubules are often described as cytoskeletal elements involved in transport, the function of the microtubule-rich cell extensions common in ovarian cells of oribatid mites is still unclear (Woodring and Cook, 1962; Witaliński, 1986; Witaliński, 1987; Taberly, 1987; Witaliński et al., 1990). Transport vesicles have not been observed in these extensions and, due to scarce information of their destination and the ultrastructure of the sarcoptiform ovarian core, it is not yet clear whether mechanical support or cellular communication is their primary function (Witaliński, 1987; Alberti and Coons, 1999;). In A. longisetosus, abundance of nuclear pores is a feature of oocytes throughout previtellogenesis and vitellogenesis (Bergmann et al., 2010), however, the microtubule-rich extensions are lost during diplotene stage, when the oocytes start their centrifugal movement during the previtellogenetic growth phase. 


\section{Implications for the reproductive mode}

While recombination events, especially the initiation of DSBs, were demonstrated to be intimately linked to SC formation in Saccharomyces cerevisiae Meyen ex E.C. Hansen, 1883 (Henderson and Keeney, 2004) and Arabidopsis thaliana (L.) Heynh. 1842 (Higgins et al., 2005), this seems not to be the case in Drosophila melanogaster Meigen 1830 (McKim et al., 1998) or in Caenorhabditis elegans (Maupas, 1900) (Dernburg et al., 1998), which also lacks recombination nodules (Page and Hawley, 2004; Colaiácovo, 2005). Formation of SCs of structure and dimensions similar to those in A. longisetosus was also described in the achiasmate spermiogenesis of $P$. communis (Welsch, 1973).

Due to the scarcity of nuclear envelope-SC associations observed in this study, and our inability to directly observe the process of SC formation, we cannot infer the complete absence of DSBs or chiasmata. Absence of recombination was suggested by molecular studies in A. longisetosus as well as other parthenogenetic oribatid mites (Palmer and Norton, 1992; Schaefer et al., 2006). Absence of evidence for recombination in both molecular as well as ultrastructural data at hand still does not rule out chiasmate meiosis. SC initiation by DSB and initiation of chiasmata is still a theoretical possibility, provided that crossovers are restricted to the non-coding telomeric region of the chromosomes, and are therefore genetically meaningless outside their putative structural function (Wrensch et al., 1994).

Terminal fusion automixis in A. longisetosus can only be reconciled with the molecular evidence of fixed heterozygosity (Palmer and Norton, 1992) by the assumption of inverted meiosis. A concept for this case was formulated earlier (Wrensch et al., 1994). It is based on the holokinetic chromosomes found in this group of animals, which also have been confirmed for A. longisetosus (Heethoff et al., 2006): If spindle fiber attachment during metaphase is not restricted to the centromere region, a $90^{\circ}$ flip of tetrad arrangement at the nuclear envelope can lead to a different sequence of separation of homologous and sister chromatids during the meiotic sequence. This form is called inverted meiosis, referring to the genetical outcome of an inverted sequence of chromatid segregation, leading to an equational first (division of sister chromatids) and reductional second meiotic division (disjunction of sister chromosomes).

In addition to spatial rearrangement, studies on other organisms exhibiting pre-reductional meiosis, such as $C$. elegans and S. cerevisiae, indicate that the inversion of the sequence of the axis-associated protein REC-8's dissociation from chromatids is required (Buonomo et al., 2000; Pasierbek et al., 2001; Rogers et al., 2002). In the described species, REC-8 is released first from the contact site of homologous chromosomes in meiosis I, and later from the contact site of sister chromosomes during meiosis II, leading to a conventional meiotic sequence. Observation of SCs in prophase I of A. longisetosus, however, indicates that inversion of the sequence of meiotic divisions, if present, must be restricted to the pattern of chromatid segregation in this species, as the formation of the $\mathrm{SC}$ is unequivocally associated with the prophase of the first meiotic division in all meiotic systems (Marec, 1996; Page and Hawley, 2004). Hence, meiosis I in A. longisetosus, although equational, may be homologous to meiosis I in non-inverted systems from a cytological point of view. However, chiasmate or achiasmate inverted meiosis can occur only with holokinetic chromosomes (Bongiorni et al., 2004; Viera et al., 2009), a prerequisite met in A. longisetosus.

Thus, a genetically postreductional situation in this case can putatively be achieved with less alteration than would be required for a complete inversion of the meiotic sequence, keeping the complex molecular background and intricate network of transcriptional processes related to meiosis in mind (e.g. Hotta et al., 1995; Perezgasga et al., 2004).

Parthenogenesis in A. longisetosus seems to be unrelated to microbial induction. For example, there is no evidence of Wolbachia infection in any member of a parthenogenetic oribatid mite clade (Perrot-Minnot and Norton, 1997). In addition, the mode of reproduction induced by Wolbachia (gamete duplication) is different from what is observed in parthenogenetic oribatid mites (Legner, 1985; Stouthamer and Kazmer, 1994), in which the easiest imaginable model that is consistent with observations is the failure of diakinesis in meiosis II (Perrot-Minnot and Norton, 1997). 


\section{Parthenogenesis}

Theoretically, terminal fusion automixis with fixed heterozygosity seems to require three steps in A. longisetosus: a) A rearrangement of the $\mathrm{SC}$, effectively a $90^{\circ}$ switch relative to the equatorial plane of the cell; b) A subsequent loss of cohesion between sister chromatids first (instead of homologous chromatids) during meiosis I, leading to inverted meiosis; and c) loss of a functional diakinesis at the end of meiosis II. If condition b) is already met, then c) leads to a diploid embryo that is the clone of its mother. Pairing of homologous as well as sister chromatids via the SC during prophase I would enable processes of DNA repair fundamentally different and of far higher fidelity (Cummings and Zolan, 1997; Perrot-Minnot and Norton, 1997; Schön and Martens, 2002) than those associated with mitosis, and thus slow down the accumulation of deleterious mutations and 'Muller's Ratchet' (Muller, 1964).

The process described above could extend the longevity of parthenogenetic lineages and, ultimately, parthenogenetic clades, but what explains the apparent frequency of their evolutionary appearance throughout the oribatid mite tree? The clades are widely dispersed and - to the extent that clade size reflects time since origin - diverse in phylogenetic age (Norton \& Palmer, 1991; Cianciolo \& Norton, 2006)

An understanding will require more general knowledge of the reproductive mechanisms in a larger selection of parthenogenetic clades as well as of bisexual species that are closely related to the parthenogens, i.e. representing their respective stem group. If conditions a) and b) (above) are consistently met in stem groups, then only the loss of diakinesis II would be needed to initiate a parthenogenetic lineage (and eventual clade). Wrensch et al. (1994) suggested that the genetic system of oribatid mites, with their holokinetic chromosomes, is 'permissive' in this context, setting the stage for multiple evolutions of parthenogenetic clades; but data remain scarce.

If only the loss of diakinesis is needed to initiate a parthenogenetic lineage or clade of oribatid mites, then conceptually the reestablishment of diakinesis could result in a revolution of bisexuality. This reversal seems to have happened at least once, within the nothrine family Crotoniidae (Domes et al., 2007b), but two other examples are possible. Astigmata, a primarily bisexual mite group, was also putatively derived within a parthenogenetic clade of Nothrina (Norton, 1998; but see Domes et al., 2007a; Dabert et al., 2010). In a more primitive oribatid group (infraorder Enarthronota), molecular data (Pachl et al., 2012) support a phylogenetic tree in which the bisexual genera of Mesoplophoridae are more derived, with the basal genus and outgroups of the family being parthenogenetic. We do not know how diakinesis is lost in parthenogenetic oribatid mites, but such reversals may be rare because either repair mechanisms rarely can 'save' the appropriate genes from mutation over long periods of time, or because appropriate back-mutation is rare.

In this context, it is an intriguing observation that cyclic parthenogenesis in Daphnia pulex LEYDIG, 1860 was recently shown to be enabled not by apomictic oogenesis as formerly suggested, but by suppression of homologue segregation during meiosis (Hiruta et al., 2010; Hiruta and Tochinai, 2012, termed 'abortive meiosis'). In their 2012 publication, the authors also explore several relatively simple deviations from the meiotic program that might lead to the evolution of obligate parthenogenesis (Hiruta and Tochinai, 2012).

Considering the similarities among distantly related arthropods like Astigmata (Heinemann and Hughes, 1969; Okabe and OConnor, 2001), bugs (Bongiorni et al., 2004; Nokkala and Nokkala, 1996; Viera et al., 2009), fruit flies (Carpenter, 1979a; Carpenter,1979b; Carpenter,2003), dragonflies (Mola, 1994) and Daphnia (Hiruta et al., 2010; Hiruta and Tochinai, 2012), automixis by failure of diakinesis during the reductional division might not be an altogether uncommon mode of parthenogenetic reproduction in unisexual arthropods. In view of progress achieved in recent years, incorporating the model species $A$. longisetosus in comparative analyses of meiosis among arthropods, and expanding research into its molecular background, could broaden our understanding of this key process in metazoan evolution. 


\section{Acknowledgments}

We thank Prof. Oliver Betz and Dr. Klaus Eisler for supporting the electron microscopical studies, and Monika Meinert for excellent assistance with sample preparation and sectioning.

Paavo Bergmann expresses his gratitude towards Evangelisches Studienwerk Villigst e.V.

for receiving a $\mathrm{PhD}$ grant.

\section{References}

Alberti G., Coons L.B. 1999. Acari - Mites. In: Harrison F.W. and Foelix R.F. (Eds). Microscopic Anatomy of Invertebrates, Vol. 8C. New York: Wiley - Liss, Inc. p. 515-1265.

Bergmann P., Heethoff M. 2012. Development of the internal reproductive organs in early nymphal stages of Archegozetes longisetosus AOKI (Acari, Oribatida, Trhypochthoniidae) as obtained by synchrotron $\mathrm{X}$-ray microtomography (SR- $\mu \mathrm{CT}$ ) and transmission electron microscopy (TEM). Soil Organisms, 84(2): 459-470.

Bergmann P., Laumann M., Cloetens P., Heethoff M. 2008. Morphology of the internal reproductive organs of Archegozetes longisetosus AOKI (Acari, Oribatida). Soil Organisms, 80(2): 171-195.

Bergmann P., Laumann M., Heethoff M. 2010. Ultrastructural aspects of vitellogenesis in Archegozetes longisetosus AOKI, 1965 (Acari, Oribatida, Trhypochthoniidae). Soil Organisms, 82(2): 193-208.

Bogolyubov D. 2007. Localization of RNA transcription sites in insect oocytes using microinjections of 5-bromouridine 5'-triphosphate. Folia Histochem Cytobiol, 45: 129-134.

Bongiorni S., Fiorenzo P., Pippoletti D., Prantera G. 2004. Inverted meiosis and meiotic drive in mealybugs. Chromosoma, 112: 331-341. doi:10.1007/s00412-004-0278-4

Buonomo S. B., Clyne R.K., Fuchs J., Loidl J., Uhlmann F., Nasmyth K. 2000. Disjunction of homologous chromosomes in meiosis I depends on proteolytic cleavage of the meiotic cohesin Rec 8 by separin. Cell, 103: 387-398. doi:10.1016/S0092-8674(00)00131-8

Cardona A., Saalfeld S., Schindelin J., Arganda-Carreras I., Preibisch S., Longair M., Tomancak P., Hartenstein V., Douglas R.J. 2012. TrakEM2 Software for Neural Circuit Reconstruction. PLoS ONE, 7(6): e38011. doi:10.1371/journal.pone.0038011

Carpenter A.T.C. 1975. Electron microscopy of meiosis in Drosophila melanogaster females: II: The recombination nodule - a recombination-associated structure at pachytene. Proc. Natl. Acad. Sci. USA, 72: 3186-3189. doi:10.1073/pnas.72.8.3186

Carpenter A.T.C. 1979a. Synaptonemal complex and recombination nodules in wild-type Drosophila melanogaster females. Genetics, 92: 511-541.

Carpenter A.T.C. 1979b Recombination nodules and synaptonemal complex in recombination-defective females of Drosophila melanogaster. Chromosoma, 75: 259-292. doi:10.1007/BF00293472

Carpenter A.T.C. 2003. Normal synaptonemal complex and abnormal recombination nodules in two alleles of the Drosophila meiotic mutant mei-W68. Genetics, 163: 1337-1356.

Cianciolo, J., Norton, R.A. 2006. The ecological distribution of reproductive mode in oribatid mites, as related to biological complexity. Exp. Appl. Acarol., 40: 1. doi:10.1007/s10493-006-9016-3

Colaiácovo M.P. 2005. The many facets of SC function during C. elegans meiosis. Chromosoma, 115: 195-211. doi:10.1007/s00412-006-0061-9

Cummings W.J., Zolan M.E. 1997. 4 Functions of DNA Repair Genes during Meiosis. In: Handel M.A. (Ed.). Current Topics in Developmental Biology. Waltham: Academic Press. p. 117-140. doi:10.1016/S0070-2153(08)60173-8

Dabert M., Witaliński W., Kazmierski A., Olszanowski Z., Dabert J. 2010. Molecular phylogeny of acariform mites (Acari, Arachnida): Strong conflict between phylogenetic signal and long-branch attraction artifacts. Mol Phylogenet Evol, 56(10): 222-241. doi:10.1016/j.ympev.2009.12.020

Dernburg A.F., McDonald K., Moulder G., Barstead R., Dresser M., Villeneuve A.M. 1998. Meiotic recombination in C. elegans initiates by a conserved mechanism and is dispensable for homologous chromosome synapsis. Cell, 94: 387-398. doi:10.1016/S0092-8674(00)81481-6

Domes K., Althammer M., Norton R.A., Scheu S., Maraun M. 2007a. The phylogenetic relationship between Astigmata and Oribatida (Acari) as indicated by molecular markers. Exp Appl Acarol, 42: 159-171. doi:10.1007/s10493-007-9088-8

Domes K., Norton R.A., Maraun M., Scheu S. 2007b. Reevolution of sexuality breaks Dollo's law. Proc. Natl. Acad. Sci. USA, 104: 7139-7144. doi:10.1073/pnas.0700034104

Estrada-Venegas E.G., Norton R.A., Equihua-Martínez A., Romero Nápoles J., Trinidad Santos J., González Hernandez H. 1999. Biologia y nueva sinonimia de Archegozetes longisetosus AOKI (Acari-Oribatida) de la Mancha, Veracruz, Mexico. Folia Entomol Mex, 107: 41-50.

Fuente R. de la, Parra M.T., Viera A., Calvente A., Gómez R., Suja J. Á., Rufas J.S. and Page J. 2007. Meiotic Pairing and Segregation of Achiasmate Sex Chromosomes in Eutherian Mammals: The Role of SYCP3 Protein.PLOS Genetics 3 e198

Heethoff M., Maraun M., Scheu S. 2000. Genetische Variabilität der ribosomalen ITS 1-Sequenzen bei der parthenogenetischen Hornmilbe Platynothrus peltifer (C.L. KOCH, 1839). Ber nat-med Verein Innsbruck, 87: 339-54.

Heethoff M., Bergmann P., Norton R.A 2006. Karyology and Sex determination of Oribatid Mites. Acarologia, 46: 127-131.

Heethoff M., Laumann M., Bergmann P. 2007a. Adding to the Reproductive Biology of the Parthenogenetic Oribatid Mite, Archegozetes longisetosus (Acari, Oribatida, Trhypochthoniidae). Turk. J. Zool., 31: 151-159. 
Heethoff M., Domes K., Laumann M., Maraun M., Norton R.A., Scheu S. 2007b. High Genetic Divergences Indicate Ancient Separation of Parthenogenetic Lineages of the Oribatid Mite Platynothrus peltifer (Acari, Oribatida). J. Evolution Biol., 20(1): 392-402. doi:10.1111/j.1420-9101.2006.01183.x

Heethoff M., Laumann M., Weigmann G., Raspotnig G. 2011. Integrative taxonomy: Combining morphological, molecular and chemical data for species delineation in the parthenogenetic Trhypochthonius tectorum complex (Acari, Oribatida, Trhypochthoniidae). Frontiers Zool., 8(2). doi:10.1186/1742-9994-8-2

Heethoff M., Bergmann P., Laumann M., Norton R.A. 2013. The 20th anniversary of a model mite: a review of current knowledge about Archegozetes longisetosus (Acari, Oribatida). Acarologia, 53(4): 353-368. doi:10.1051/acarologia/20132108

Heinemann R.L., Hughes R.D. 1969. The Cytological basis for Reproductive Variability in the Anoetidae (Sarcoptiformes: Acari). Chromosoma, 28: 346-356. doi:10.1007/BF00284931

Henderson K.A., Keeney S. 2004. Tying synaptonemal complex initiation to the formation and programmed repair of DNA double-strand breaks. Proc. Natl. Acad. Sci. USA, 101: 4519-4524 doi:10.1073/pnas. 0400843101

Higgins J.D., Sanchez-Moran E., Armstrong S.J., Jones G.H., Franklin F.C.H. 2005. The Arabidopsis synaptonemal complex protein ZYP1 is required for chromosome synapsis and normal fidelity of crossing over. Genes Dev, 19: 2488-2500. doi:10.1101/gad.354705

Hiruta C., Tochinai S. 2012. How does the alteration of meiosis evolve to parthenogenesis?- Case Study in a Water Flea, Daphnia pulex -. In: Swan A. (Ed.) Meiosis - Molecular Mechanisms and Cytogenetic Diversity. InTech. doi: $10.5772 / 29558$

Hiruta C., Nishida C., Tochinai S. 2010. Abortive meiosis in the oogenesis of parthenogenetic Daphnia pulex. Chromosome Res, 18: 833-840. doi:10.1007/s10577-010-9159-2

Hotta Y., Furukawa K., Tabata S. 1995. Meiosis specific transcription and functional proteins. Adv Biophys, 31: 101-115. doi:10.1016/0065-227X(95)99386-4

Laumann M., Norton R.A., Weigmann G., Scheu S., Maraun M., Heethoff M. 2007. Speciation in the Parthenogenetic Oribatid Mite Genus Tectocepheus (Acari, Oribatida) as Indicated by Molecular Phylogeny. Pedobiologia, 51(2): 111-22. doi:10.1016/j.pedobi.2007.02.001

Laumann M., Bergmann P., Heethoff M. 2008. Some remarks on the cytogenetics of oribatid mites. Soil Organisms, 80(2): 223-232.

Laumann M., Norton R.A., Heethoff M. 2010. Acarine embryology: Inconsistencies, artificial results and misinterpretations. Soil Organisms, 82(2): 217-135.

Legner E.F. 1985. Effects of scheduled high temperature on male production in thelytokous Muscidifurax uniraptor (Hymenoptera: Pteromalidae). Can Entomol, 117: 383-389. doi:10.4039/Ent117383-3

Maraun M., Heethoff M., Schneider K., Scheu S., Weigmann G., Cianciolo J., Thomas R.H., Norton R.A. 2004. Molecular phylogeny of oribatid mites (Oribatida, Acari): evidence for multiple radiations of parthenogenetic lineages. Exp. Appl. Acarol., 33: 183-201. doi:10.1023/B:APPA.0000032956.60108.6d

Marec F. 1996. Synaptonemal Complexes in Insects. Int J Insect Morphol Embryol, 25: 205-233. doi:10.1016/0020-7322(96)00009-8

Mark Welch D., Meselson M. 2000. Evidence for the Evolution of Bdelloid Rotifers without Sexual Reproduction or Genetic Exchange. Science, 288(5469): 1211-1215, doi:10.1126/science.288.5469.1211

Maynard Smith J., 1978.The Evolution of Sex.Cambridge: Cambridge University Press.

McKim K.S., Jang J.K., Manheim E.A. 2002. Meiotic Recombination and Chromosome Segregation in Drosophila Females. Annual Rev Gene, 36: 205-232. doi:10.1146/annurev.genet.36.041102.113929

Mola L.M. 1994. Post-reductional meiosis in Aeshna ((Aeshnidae, Odonata). Hereditas 122: 47-55. doi:10.1111/i.1601-5223.1995.00047.x

Moses M.J. 1956a. Studies on nuclei using correlated cytochemical, light, and electron microscope techniques. J Biophys Biochem Cytol, 2: 397-406. doi:10.1083/jcb.2.4.397

Moses M.J. 1956b. Chromosomal Structures in Crayfish Spermatocytes. J. Biophys. Biochem. Cytol., 2: 215-218. doi:10.1083/jcb.2.2.215

Muller H.J. 1964. The relation of recombination to mutational advance. Mutat. Res. - Fund. Mol. M., 1: $2-9$.

Nokkala S., Nokkala C. 1996. The absence of chiasma terminalization and inverted meiosis in males and females of Myrmus miriformis FN. (Corizidae, Heteroptera). Heredity, 78: 561-566. doi: 10.1038/hdy.1997.87

Norton R.A. 1998. Morphological evidence for the evolutionary origin of Astigmata. Exp. Appl. Acarol., 22: 559-594. doi:10.1023/A:1006135509248

Norton R.A., Palmer S.C. 1991. The distribution, mechanisms and evolutionary significance of parthenogenesis in oribatid mites. In: Schuster R., Murphy P.W. (Eds.). The Acari: Reproduction, Development and Life History Strategies. London: Chapman and Hall. p. 107-136. doi:10.1007/ 978-94-011-3102-5_7

Norton R.A., Sanders F. 1985. Superior micro-needles for manipulating and dissecting soil invertebrates. Quest. Entomol., 21: 673-674.

Okabe K., OConnor B.M. 2001. Thelytokous reproduction in the family Acaridae (Astigmata). In: Halliday R.B., Walter D.E., Proctor H.C., Norton R.A., Colloff M.J. (Eds.). Acarology: Proceedings of the 10th International Congress. Canberra: CSIRO Publishing. p. 170-175.

Pachl P., Domes K., Schulz G., Norton R.A., Scheu S., Schaefer I.; Maraun M. 2012 Convergent evolution of defense mechanisms in oribatid mites (Acari, Oribatida) shows no "ghosts of predation past". Mol. Phylogenet. Evol., 65: 412-420. doi:10.1016/j.ympev.2012.06.030

Page S.L., Hawley R.S. 2004. The genetics and molecular biology of the synaptonemal complex. Ann. Rev. Cell. Dev. Biol., 20: 525-558. doi:10.1146/annurev.cellbio.19.111301.155141

Palmer S.C., Norton R.A. 1990. Further Experimental Proof of Thelytokous Parthenogenesis in Oribatid Mites (Acari: Oribatida: Desmonomata). Exp. Appl. Acarol., 8: 149-159. doi:10.1007/BF01194176 
Palmer S.C., Norton R.A. 1991. Taxonomic, geographic and seasonal distribution of thelytokous parthenogenesis in the Desmonomata (Acari, Oribatida). Exp. Appl. Acarol., 12: 67-81. doi: 10.1007/BF01204401

Palmer S.C., Norton R.A. 1992. Genetic Diversity in Thelytokous Oribatid Mites (Acari; Acariformes: Desmonomata). Biochem. Syst. Ecol., 20: 219-231. doi:10.1016/0305-1978(92)90056-J

Pasierbek P., Jantsch M., Melcher M., Schleiffer A., Schweizer D., Loidl J. 2001. A Caenorhabditis elegans cohesion protein with functions in meiotic chromosome pairing and disjunction. Genes Dev., 15: 1349-1360. doi:10.1101/gad.192701

Perezgasga L., Jiang J., Bolival B., Hiller M., Benson E., Fuller M.T., White-Cooper H. 2004. Regulation of transcription of meiotic cell cycle and terminal differentiation genes by the testis-specific Zn-finger protein matotopetli. Development, 131: 1691-1702. doi:10.1242/dev.01032

Perrot-Minnot M-J., Norton R.A. 1997. Obligate Thelytoky in oribatid mites: No evidence for Wolbachia inducement. Can. Entomol., 129: 691-698. doi:10.4039/Ent129691-4

Qiao H., Chen J.K., Reynolds A., Höög C., Paddy M., Hunter N. 2012. Interplay between Synaptonemal Complex, Homologous Recombination, and Centromeres during Mammalian Meiosis. PLOS Genetics 8, e1002790. doi:10.1371/journal.pgen.1002790

Rogers E., Bishop J.D., Waddle J.A., Schumacher J.M., Lin R. 2002. The aurora kinase AIR-2 functions in the release of chromosome cohesion in Caenorhabditis elegans meiosis. J. Cell. Biol., 157: 219-229. doi:10.1083/jcb.200110045

Saalfeld S., Cardona A., Hartenstein V., Tomancak P. 2010. As-rigid-as-possible mosaicking and serial section registration of large ssTEM datasets. Bioinformatics, 26(12), i57-i63. doi:10.1093/bioinformatics/ bta219

Schaefer I., Domes K., Heethoff M., Schneider K., Schön I., Norton R.A., Scheu S., Maraun M. 2006. No evidence for the "Meselson effect" in parthenogenetic oribatid mites (Oribatida, Acari). J. Evol. Biol., 19: 184-193. doi:10.1111/j.1420-9101.2005.00975.x

Schön I., Martens K. 2002. No slave to sex. Proc. R. Soc. Lond. B. Biol. Sci., 270: 827-833. doi:10.1098/rspb.2002.2314

Schwander T. 2016. Evolution: The End of an Ancient Asexual Scandal. Current Biology, 26(6): pR233-R235 doi:10.1016/j.cub.2016.01.034

Stouthamer R., Kazmer D.J. 1994. Cytogenetics of microbe-associated thelytoky and its consequences for gene flow in Trichogramma wasps. Heredity, 73: 317-327. doi:10.1038/hdy.1994.139

Taberly G. 1987. Recherches sur la parthénogenèse thélytoque de deux espèces d'acariens oribates Trhypochthonius tectorum (Berlese) et Platynothrus peltifer (Koch). III. Étude Anatomique, Histologique et Cytologique des femelles parthénogénétique. $2^{\mathrm{eme}}$ Partie. Acarologia, 28: 389-403.

Venable J.H., Coggeshall R. 1965. A simplified lead citrate stain for use in electron microscopy. J. Cell. Biol., 25: 407-408. doi:10.1083/jcb.25.2.407

Viera A., Page J., Rufas J.S. 2009. Inverted Meiosis: The True Bugs as a Model to Study. In: Benavente R., Volff J-N. (Eds.) Genome Dynamics, Vol 5: Meiosis. Basel: KARGER. p. 137-156.

Welsch B. 1973. Synaptonemal Complex und Chromosomenstruktur in der achiasmatischen Spermatogenese von Panorpa communis (Mecoptera). Chromosoma, 43(1):19-74. doi:10.1007/BF01256732

Witaliński W. 1986. Egg-shells in mites I. A comparative ultrastructural study of vitelline envelope formation. Cell Tissue Res., 244: 209-214. doi:10.1007/BF00218401

Witaliński W. 1987. Topographical relations between oocytes and other ovarian cells in three mite species (Acari). Acarologia, 28: 297-306.

Witaliński W., Szlendak E., Boczek J. 1990. Anatomy and ultrastructure of the reproductive systems of Acarus siro (Acari: Acaridae). Exp. Appl. Acarol., 10: 1-31. doi:10.1007/BF01193970

Woodring J.P., Cook E.F. 1962. The Internal Anatomy, Reproductive Physiology, and Molting Process of Ceratozetes cisalpinus (Acarina: Oribatei). Ann. Entomol. Soc. Am., 55: 164-181. doi: 10.1093/aesa/55.2.164

Wrensch D.L., Kethley J.B., Norton R.A. 1994. Cytogenetics of Holokinetic Chromosomes and Inverted Meiosis: Keys to the Evolutionary Success of Mites, with Generalizations on Eukaryotes. In: Houck M.A. (Ed.). Mites - Ecological and Evolutionary Analyses of Life-History Patterns. New York, London: Chapman\&Hall. p. 282-342.

Zetka M. 2009. Homologue Pairing, Recombination and Segregation in Caenorhabditis elegans. In: Benavente R, Volff J-N (Eds.) Genome Dynamics, Vol. 5: Meiosis. Basel: KARGER. p. 43-55. 